nghiên cứu in vivo để xác nhận kết quả của nghiên cứu này.

\section{KẾT LUẬN}

Ảnh hưởng của gel $\mathrm{CHX}$ ở nồng độ pha loãng $1 / 10^{3}$ và $1 / 10^{4}$ lên một số đặc tính sinh học của NBSN tương đương gel đối chiếu (PerioKin ${ }^{\circledR}$ ) được sử dụng hiệu quả trên lâm sàng hiện nay. Gel nghiên cứu của chúng tôi là một loại gel đảo ngược bởi nhiệt có ưu điểm làm tăng thời gian lưu trú của hoạt chất và tăng hiệu quả điều trị.

LỜI CẢM ƠN: Cám ơn TS Huỳnh Trúc Thanh Ngọc-Khoa Dược, ĐHY Dược TP.HCM đã cung cấp mẫu nghiên cứu cho chúng tôi.

\section{TÀI LIẸU THAM KHẢO}

1. Ban Zuhair A. (2020), "The Efficacy of Chlorhexidine Gel as an Adjunctive Treatment for Patient with Chronic Periodontitis", Indian Journal of Forensic Medicine \&amp; Toxicology. 14(1), pp. 544-550.

2. Garala K., Joshi P., Shah M., Ramkishan A. and Patel J. (2013), "Formulation and evaluation of periodontal in situ gel", Int J Pharm Investig. 3(1), pp. 29-41.

3. Nie S., Hsiao W. L., Pan W. and Yang $Z$. (2011), "Thermoreversible Pluronic F127-based hydrogel containing liposomes for the controlled delivery of paclitaxel: in vitro drug release, cell cytotoxicity, and uptake studies", Int J Nanomedicine. 6, pp. 151-66.

4. Li R., Guo W., Yang B., Guo L., Sheng L., Chen G., Li Y., Zou Q., Xie D., An X., Chen Y. and Tian W. (2011), "Human treated dentin matrix as a natural scaffold for complete human dentin tissue regeneration", Biomaterials. 32(20), pp. 4525-38.

5. Liang C. C., Park A. Y. and Guan J. L. (2007), "In vitro scratch assay: a convenient and inexpensive method for analysis of cell migration in vitro", Nat Protoc. 2(2), pp. 329-33.

6. Colombo M., Ceci M., Felisa E., Poggio C. and Pietrocola G. (2018), "Cytotoxicity evaluation of a new ozonized olive oil", European journal of dentistry. 12(4), pp. 585-589.

7. Sukumaran S. K., Vadakkekuttical R. J. and Kanakath H. (2020), "Comparative evaluation of the effect of curcumin and chlorhexidine on human fibroblast viability and migration: An in vitro study", J Indian Soc Periodontol. 24(2), pp. 109-116.

8. Mercan U., Gonen Z. B., Salkin H., Yalcin Ulker G. M. and Meral D. G. (2019), "Comparison of the effect of postoperative care agents on human gingival fibroblasts: a preliminary study", Eur Oral Res. 53(2), pp. 67-73.

9. Cabral C. T. and Fernandes M. H. (2007), "In vitro comparison of chlorhexidine and povidoneiodine on the long-term proliferation and functional activity of human alveolar bone cells", Clin Oral Investig. 11(2), pp. 64-155.

\title{
KIẾN THỨC, THỰC HÀNH VỀ CHĂM SÓC TRƯớC SINH VÀ MộT SỐ YẾU TỐ LIÊN QUAN Ở PHU NỮ Có CON DƯớI 6 THÁNG TUỔI TẠI 2 XÃ/PHƯỜNG TỈNH THỪA THIÊN HUẾ NĂM 2019
}

\section{TÓM TẮT}

Muc tiêu: Nghiên cứu mô tả cắt ngang được thực hiện ở 2 xã/phường của tỉnh Thừa Thiên Huế năm 2019 nhằm mô tả kiến thức và thực hành của phu nữ có con dưới 6 tháng tuổi về chăm sóc trước sinh và một số yếu tố liên quan. Đối tượng và phương pháp: Đối tượng là bà mẹ có con dưới 6 tháng tuổi. Sử dụng bộ câu hỏi có cấu trúc, kiến thức và thực hành được đánh giá dựa trên Hướng dẫn quốc gia về các dịch vụ chăm sóc sức khỏe sinh sản của Bộ Y tế. Kết quả: Kết quả cho thấy tỷ lệ bà mẹ có kiến thức tốt và thực hành tốt về chăm sóc trước sinh lần lượt là

\footnotetext{
${ }^{1}$ Bệnh Viện Đa Khoa Quốc Tế Hoàn Mỹ Thủ Đức, Thành phố Hồ Chí Minh

${ }^{2}$ Trường Đại học Y Dược, Đại học Huê

Chịu trách nhiệm chính: Nguyễn Thị Nga

Email: nganguyen@huemed-univ.edu.vn

Ngày nhận bài: 3.3.2021

Ngày phản biên khoa học: 23.4.2021

Ngày duyệt bài: 5.5.2021
}

\begin{abstract}
Nguyễn Thị Bích Trâm ${ }^{1}$, Nguyễn Thị $\mathbf{N g a}^{2}$
$60,8 \%$ và $63,1 \%$. Trình độ học vấn, nghề nghiệp, số lần sinh con là những yếu tổ có liên quan đến kiến thức tốt. Các yếu tố liên quan đến thực hành tốt bao gồm: trình độ học vấn, nghề nghiệp, nơi sinh sống, số lần mang thai, số lần sinh con và kiến thức về chăm sóc trước sinh $(p<0.05)$. Kết luận: Do vậy, cần tăng cường truyền thông giáo dục sức khỏe, tư vấn cho phu nữ trước và trong khi mang thai để phu nữ có kiến thức đúng và đây đủ, từ đó thực hành tốt chăm sóc trước sinh.
\end{abstract} hành

Tư khóa: Chăm sóc trước sinh; kiến thức; thực

\section{SUMMARY}

KNOWLEDGE, PRACTICES OF ANTENATAL CARE AND ASSOCIATED FACTORS AMONG WOMEN WHO HAD CHILDREN AGED UNDER 6-MONTH AT 2 COMMUNES/WARDS OF

THUA THIEN HUE PROVINCE IN 2019

A cross-sectional descriptive study was conducted at 2 communes/wards of Thua Thien Hue province in 2019 to describe the knowledge and practices of 
antenatal care among women who had children aged under 6-month and associated factors. Using a structured questionnaire, knowledge and practices of antenatal care were assessed based on National Guidelines for Reproductive Health Care Service of the Ministry of Health. The results showed that the percentage of mothers achieving good knowledge and practices of antenatal care were $60.8 \%$ and $63.1 \%$, respectively. Education level, occupation, number of births were associated factors with good knowledge. Factors associated with good practices include education level, occupation, place of residence, number of pregnancies, number of births, knowledge of antenatal care $(p<0.05)$. Thus, it is essential to enhance reproductive health education and communication, give counsel for women before and during pregnancy so that women could acquire accurate and comprehensive knowledge, thereby perform good practices of antenatal care.

Keywords: Antenatal care; knowledge; practices

\section{I. ĐĂT VẤN ĐỀ}

Mang thai và sinh đẻ là nguyên nhân hàng đầu gây bệnh tật và tử vong mẹ, với $99 \%$ các trường hợp tử vong này xảy ra ở các nước đang phát triển. Theo ước tính toàn câu của Liên Hợp Quốc, khoảng 303.000 phụ nữ tử vong mỗi năm trong quá trình sinh đẻ hoặc là kết quả của các biến chứng phát sinh từ thai kỳ. Điều này tương đương với khoảng 830 phụ nữ tử vong mỗi ngày do các nguyên nhân có thể phòng chống được liên quan đến mang thai và sinh đẻ. Ước tính mỗi năm nước ta vẫn còn khoảng 580-600 trường hợp tử vong me và khoảng trên 10.000 trường hợp tử vong trẻ sơ sinh [2]. Chăm sóc trước sinh (CSTS) đóng vai trò quan trọng trong chiến lược giảm tỷ lệ tử vong mẹ thông qua khám thai và sử dụng các dịch vụ CSTS trong quá trình mang thai, tiêm chủng, khám sàng lọc, tư vấn dinh dưỡng, lối sống. Các can thiệp dự phòng và điêu trị trong giai đoạn mang thai có hiệu quả cao trong việc dự phò̀ng các tai biến trong quá trình mang thai cũng như khi sinh [9]. Tuy nhiên, không phải thai phụ nào cũng hiểu biết được giá trị của CSTS và thực hành có hiệu quả. Việc nâng cao sức khỏe bà me là cũng một nội dung quan trọng đã được Thủ tướng Chính phủ đưa vào một trong những mục tiêu của Chiến lược Dân số và Sức khỏe sinh sản Việt Nam giai đoạn 2011-2020.

ở tỉnh Thừa Thiên Huế, một số nghiên cứu trong những năm trước đây cho thấy tỷ lệ các bà mẹ có kiến thức và thực hành đúng về CSTS còn chưa cao. Với sự phát triển của kinh tế xã hội, sự phổ biến của mạng Internet và sự thành công của các chương trình y tế quốc gia đã góp phần tạo điều kiện cho việc nâng cao kiến thức, thay đổi hành vi về chăm sóc sức khỏe sinh sản nói chung và CSTS nói riêng của phụ nữ mang thai. Bên cạnh đó, Bộ $Y$ tế đã ban hành "Hướng dẫn quốc gia về các dịch vụ chăm sóc sức khỏe sinh sản" vào năm 2016 với một số thay đổi so với "Hướng dẫn quốc gia về các dịch vụ chăm sóc sức khỏe sinh sản" năm 2009, từ đó đển nay, chưa có nhiều nghiên cứu được thực hiện để khảo sát về vấn đề CSTS này. Từ những thực tế trên, chúng tôi thực hiện đề tài này nhằm mô tả kiến thức, thực hành về CSTS ở phụ nữ có con dưới 6 tháng tuổi và tìm hiểu một số yếu tố liên quan.

\section{II. ĐỐI TƯợNG VÀ PHƯƠNG PHÁP NGHIÊN CỨU}

2.1. Đối tượng nghiên cứu. Đối tượng của nghiên cứu này là phụ nữ có con dưới 6 tháng tuổi, hiện đang sinh sống và có hộ khẩu thường trú tại xã Thủy Vân, thị xã Hương Thủy và phường Tây Lộc, thành phố Huế, tỉnh Thừa Thiên Huế.

2.2. Thời gian và địa điểm nghiên cứu. Nghiên cứu được tiến hành từ tháng 11 năm 2019 đến tháng 04 năm 2020 tại xã Thủy Vân, thị xã Hương Thủy và phường Tây Lộc, thành phố Huế, tỉnh Thừa Thiên Huế.

2.3. Thiết kế nghiên cứu. Sử dụng thiết kế nghiên cứu mộ tả cắt ngang.

2.4. Cỡ mẫu. Toàn bộ phụ nữ có con dưới 6 tháng tuổi tại xã Thủy Vân và phường Tây Lộc được đưa vào nghiên cứu. Tính đến 11/2019, tại địa bàn nghiên cứu có tổng cộng 179 phụ nữ có con dưới 6 tháng tuổi, trong đó xã Thủy Vân có 85 người và phường Tây Lộc có 94 người. Thực tế, thu thập thông tin được 176 phụ nữ do có 3 người đi xa trong khoảng thời gian nghiên cứu (Cụ thể ở xã Thủy Vân có 85 phụ nữ và phường Tây Lộc có 91 phụ nữ).

2.5. Phương pháp thu thập số liệu. Nghiên cứu này sử dụng bộ câu hỏi có cấu trúc đã soạn sẵn với nguyên tắc không gợi ý đáp án khi phỏng vấn để thu thập số liệu. Dựa vào lịch tiêm chủng hằng tháng tại Trạm, điều tra viên thu thập số liệu tại các buổi tiêm chủng mơ rộng. Sau khi buổi thu thập số liệu ở ngày tiêm chủng mở rộng, dò lại danh sách những bà mẹ chưa được phỏng vấn. Những bà me này được phỏng vấn tại nhà. Sau mỗi buổi thu thập số liệu, kiểm tra chéo lại bộ câu hỏi để kiểm tra và làm sạch số liệu ngay trong ngày.

2.6. Đánh giá kiến thức và thực hành chăm sóc trước sinh. Bộ câu hỏi dùng để đánh giá kiến thức và thực hành CSTS được xây dựng dựa trên "Hướng dẫn quốc gia về các dịch vụ chăm sóc sức khỏe sinh sản" năm 2016 của Bộ Y 
tễ, gồm các nội dung: đi khám thai, tiêm phòng uốn ván, uống bổ sung sắt và acid folic, sử dụng thuốc điều trị bệnh, làm các xét nghiệm cần thiết, chế độ dinh dưỡng, lao động và vệ sinh trong quá trình mang thai [1].

Cho điểm từng câu trả lời với từng nội dung cụ thể. Thang điểm đánh giá kiến thức về CSTS gồm 15 câu hỏi với tổng điểm là 36 điểm. Nếu đối tượng nghiên cứu đạt được $75 \%$ tổng số điểm, được đánh giá tốt.

Đối với thực hành CSTS, thang điểm đánh giá gồm 13 câu hỏi với tổng điểm là 26 điểm. Nếu đối tượng nghiên cứu đạt được $75 \%$ tổng số điểm cùng với các điều kiện: khám thai $\geq 4$ lần, tiêm vắc xin phòng uốn ván đầy đủ, có uống bổ sung viên sắt và acid folic trong thời kỳ mang thai thì được đánh giá tốt.

2.7. Phân tích số liệu. Nhập và xử lý số liệu bằng phần mềm Epidata 3.1 và SPSS 20.0. Mô tả đặc điểm chung của đối tượng nghiên cứu, kiến thức và thực hành về CSTS bằng cách tính tân số và tỷ lệ \%. Thống kê phân tích: sử dụng kiểm định Chi bình phương $(\chi 2)$ với độ tin cậy $95 \%$ để kiểm định mối liên quan giữa các biến độc lập và biến phụ thuộc. Kết luận có mối liên quan khi $\mathrm{p}<0,05$.

2.8. Đạo đức nghiên cứu. Đối tượng được giải thích rõ ràng về mục tiêu nghiên cứu và có quyên từ chối tham gia vào nghiên cứu. Các thông tin và số liệu thu được được giữ bí mật, chỉ dành cho mục đích nghiên cứu khoa học, không được phép dùng cho các mục đích khác. Hoàn toàn trung thực với các số liệu, kết quả nghiên cứu.

\section{KẾT QUẢ NGHIÊN CỨU}

Bảng 1. Đặc điểm chung của đối tượng nghiên cứu

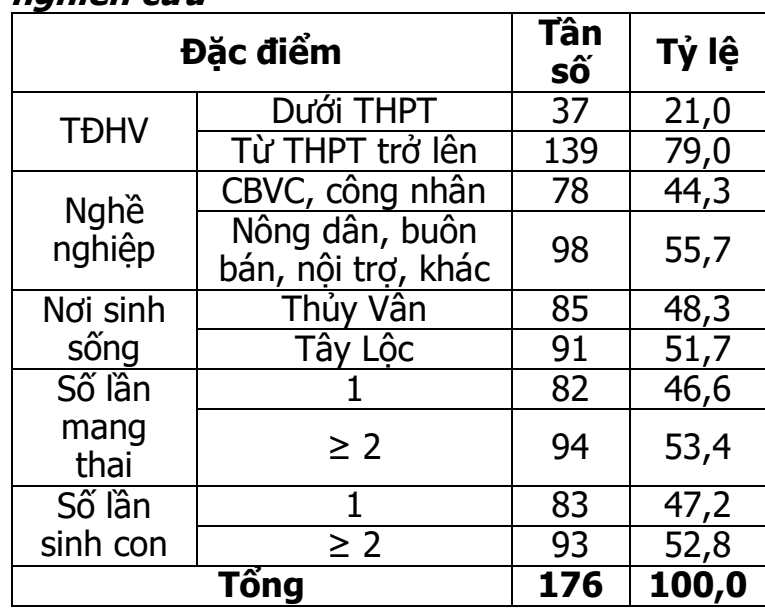

Nghiên cứu được thực hiện trên 176 đốl tượng, trong đó có 85 bà mẹ sinh sống ở xã Thủy Vân và 91 bà mẹ ở phường Tây Lộc. Có $78,4 \%$ bà me nằm trong độ tuổi từ 25-35. Bà mẹ không theo tôn giáo nào chiếm đa số $(65,3 \%)$. Phần lớn bà me có trình độ học vấn (TĐHV) từ trung học phổ thông (THPT) trở lên (79,0\%). Nghề nghiệp chính là Nông dân, buôn bán, nội trợ, khác chiếm đa số $(55,7 \%)$. Đa số bà mẹ mang thai và sinh con từ lần thứ 2 trở đi.

Bảng 2. Kiên thức và thực hành về các vấn đề trong chăm sóc trước sinhNội dung

\begin{tabular}{|c|c|c|c|c|}
\hline \multirow[t]{2}{*}{ (2) } & \multicolumn{2}{|c|}{ Kiến thức } & \multicolumn{2}{|c|}{ Thực hành } \\
\hline & Tân số & Tỷ lệ & Tân số & Tỷ lệ \\
\hline Đi khám thai ít nhất 4 lần & 119 & 67,6 & 154 & 87,5 \\
\hline Tiêm vắc xin phòng uốn ván đầy đủ & 148 & 84,1 & 156 & 88,6 \\
\hline Bố sung sắt và acid folic & 84 & 47,7 & 151 & 85,8 \\
\hline Uống thuốc điều trị bênh trong khi mang thai & 83 & 47,2 & 172 & 97,7 \\
\hline Xét nghiệm máu và nước tiểu & 143 & 81,3 & 148 & 84,1 \\
\hline Xét nghiệm sàng lọc trước sinh & 83 & 47,2 & 122 & 69,3 \\
\hline Mức cân nặng tăng trong khi mang thai & 107 & 60,8 & 145 & 82,4 \\
\hline Àn nhiều hơn bình thường & 121 & 68,8 & 105 & 59,7 \\
\hline $\begin{array}{c}\text { Ån đủ các nhóm thức ăn (chất đạm, chất đường, } \\
\text { chất béo, chất khoáng) }\end{array}$ & 166 & 94,3 & 140 & 79,5 \\
\hline Lao động nhẹ nhàng, vừa sức, xen kẽ nghỉ ngơi & 159 & 90,3 & 171 & 97,2 \\
\hline Tăm rửa thân thế sạch sẽ hằng ngày & 176 & 100,0 & 176 & 100,0 \\
\hline
\end{tabular}

Đa số bà me có hiếu biết về các nội dung trong CSTS, trong đó có kiến thức tốt nhất về chế độ dinh dưỡng, lao động và vệ sinh. Tỷ lệ bà mẹ có kiến thức về việc bổ sung sắt, acid folic, uống thuốc điều trị bệnh trong quá trình mang thai, thực hiện xét nghiệm sàng lọc trước sinh chưa cao.

Về thực hành, phần lớn các bà mẹ đều thực hành tốt các nội dung về CSTS, tỷ lệ cao các bà mẹ thực hiện tốt các nội dung quan trọng như đi khám thai ít nhất 4 lần, tiêm vắc xin phòng uốn ván đầy đủ, bổ sung sắt và acid folic. 
Bảng 3. Đánh giá kiến thức và thực hành về chăm sóc trước sinh

\begin{tabular}{|c|c|c|c|c|}
\hline \multirow{2}{*}{ Phân loại } & \multicolumn{2}{|c|}{ Kiến thức } & \multicolumn{2}{c|}{ Thực hành } \\
\cline { 2 - 5 } & Tần số & Tỷ lệ & Tần số & Tỷ lệ \\
\hline Tốt & 107 & 60,8 & 111 & 63,1 \\
\hline Chưa tốt & 69 & 39,2 & 65 & 36,9 \\
\hline Tống & $\mathbf{1 7 6}$ & $\mathbf{1 0 0}$ & $\mathbf{1 7 6}$ & $\mathbf{1 0 0}$ \\
\hline
\end{tabular}

Tỷ lê bà me có kiến thức tốt và thực hành tốt về CSTS lần lướt là 60,8 và $63,1 \%$

Bảng 4. Các yêu tố liên quan đến kiến thức về chăm sóc trước sinh

\begin{tabular}{|c|c|c|c|c|c|c|c|}
\hline \multirow{3}{*}{\multicolumn{2}{|c|}{ Đặc điểm }} & \multicolumn{4}{|c|}{ Kiến thức về CSTS } & \multirow{3}{*}{ Tổng } & \multirow{3}{*}{$\mathbf{p}$} \\
\hline & & \multicolumn{2}{|c|}{ Tốt } & \multicolumn{2}{|c|}{ Chưa tốt } & & \\
\hline & & $\mathbf{n}$ & $\%$ & $\mathbf{n}$ & $\%$ & & \\
\hline \multirow[b]{2}{*}{ TĐHV } & Dưới THPT & 10 & 27,0 & 27 & 73,0 & 37 & \multirow[b]{2}{*}{$p<0,001$} \\
\hline & Từ THPT trở lên & 97 & 69,8 & 42 & 30,2 & 139 & \\
\hline \multirow[b]{2}{*}{ Nghề nghiệp } & CBVC, công nhân & 60 & 76,9 & 18 & 23,1 & 78 & \multirow[b]{2}{*}{$p<0,001$} \\
\hline & $\begin{array}{l}\text { Nông dân, buôn bán, } \\
\text { nội trớ, khác }\end{array}$ & 47 & 48,0 & 51 & 52,0 & 98 & \\
\hline \multirow{2}{*}{ Nơi sinh sống } & Thủy Vân & 46 & 54,1 & 39 & 45,9 & 85 & \multirow{2}{*}{$p=0,079$} \\
\hline & Tây Lộc & 61 & 67,0 & 30 & 33,0 & 91 & \\
\hline \multirow{2}{*}{$\begin{array}{c}\text { Số lần mang } \\
\text { thai }\end{array}$} & 1 & 56 & 68,3 & 26 & 31,7 & 82 & \multirow{2}{*}{$p=0,057$} \\
\hline & $\geq 2$ & 51 & 54,3 & 43 & 45,7 & 94 & \\
\hline \multirow{2}{*}{$\begin{array}{l}\text { Số lần } \\
\text { sinh con }\end{array}$} & 1 & 57 & 68,7 & 26 & 31,3 & 83 & \multirow{3}{*}{$p=0,043$} \\
\hline & $\geq 2$ & 50 & 53,8 & 43 & 46,2 & 93 & \\
\hline & rống & 107 & 60,8 & 69 & 39,2 & 176 & \\
\hline
\end{tabular}

Kết quả ở bảng 4 cho thấy, có mối liên quan giữa kiến thức tốt với TĐHV, nghề nghiệp, số lần sinh con của bà me. Nhóm bà me có TĐHV từ THPT trở lên kiến thức tốt cao hơn nhóm còn lại. Nhóm bà me có nghề nghiệp là cán bộ viên chức (CBVC), công nhân, nhóm bà me sinh con lần đẩu có kiến thức tốt cao hơn nhóm còn lại. Các sự khác biệt này có ý nghĩa thống kê với $p<0,05$.

Bảng 5. Các yêu tố liên quan đến thực hành về chăm sóc trước sinh

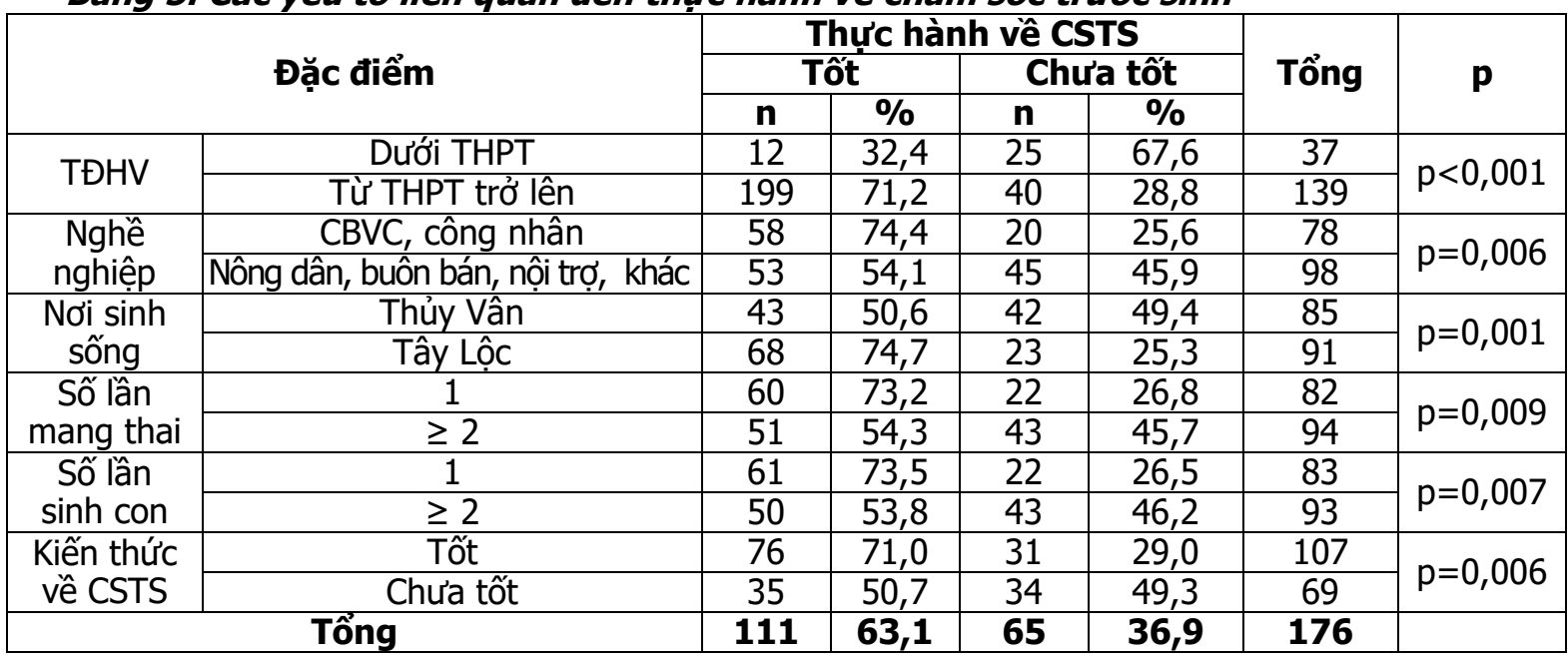

Kết quả cho thấy TĐHV, nghề nghiệp, nơi sinh sống, số lần mang thai, số lần sinh con và kiến thức về CSTS là các yếu tố có liên quan đến thực hành CSTS của bà mẹ. Theo đó, nhóm bà mẹ có TĐHV từ THPT trở lên, nghề nghiệp là CBVC, công nhân, sinh sống tại phường Tây Lộc, mang thai lần đầu, sinh con lần đầu, có kiến thức CSTS tốt thực hành tốt về CSTS cao hơn so với nhóm còn lại. Các sự khác biệt này có ý nghĩa thống kê $(p<0,05)$.

\section{BÀN LUÂN}

Kết quả nghiên cứu đã cho thấy, tỷ lệ bà me có kiến thức tốt về CSTS là $60,8 \%$, tương tự với nghiên cứu thực hiện tại huyện Hòa Vang, thành phố Đà Nẵng [4]. Điều này có thể là do phương pháp nghiên cứu của cả hai nghiên cứu có nhiều nét tương đồng và đều đánh giá kiến thức về CSTS của bà mẹ dựa vào những nội dung hướng 
dẫn của Bộ $Y$ tế trong Hướng dẫn quốc gia về các dịch vụ chăm sóc sức khỏe sinh sản. Có $63,1 \%$ bà me thực hành tốt về CSTS, so với nghiên cứu trước đây như nghiên cứu của Nguyễn Chiến Thắng $(29,8 \%)$, Lê Thị Thu Huyên $(41,5 \%)$ thì kết quả của chúng tôi cao hơn [3], [6]. Sự khác biệt này có thể là do có sự khác nhau về địa bàn và thời gian nghiên cứu. Theo thời gian, các bà me được tiếp cận đầy đủ hơn các dịch vụ chăm sóc sức khỏe trong thời gian mang thai.

Đánh giá các mục riêng rẽ về vấn đề CSTS, kết quả ở bảng 2 cho thấy ứng với từng nội dung cụ thể, tỷ lệ các bà me có thực hành đúng có phần nhỉnh hơn so với kiến thức của họ. Điều này có thể giải thích là vì trong quá trình mang thai, nhiều đối tượng nhận được sự tư vấn, hướng dẫn và làm theo lời dặn của cán bộ y tế, ví dụ như đi khám thai, tiêm phòng uốn ván, làm các xét nghiệm,... theo lịch hẹn nhưng chưa có sự tìm hiểu kĩ nên khi khảo sát kiến thức về CSTS với nguyên tắc không gợi ý đáp án khi phỏng vấn, nhiều đối tượng không nhớ, nhớ không chính xác hay không đầy đủ những nội dung này.

Nghiên cứu của chúng tôi cũng tìm thấy một số yếu tố liên quan đến kiến thức tốt, thực hành tốt về CSTS. Có mối liên quan giữa TĐHV với kiến thức về CSTS, tương tự với các nghiên cứu của Amanpreet Kaur cùng cộng sự [7]. Kết quả này là phù hợp bởi mức độ nhận thức, mức độ tìm hiểu về CSTS ở các đối tượng có TĐHV cao thường cao hơn so với các đối tượng có TĐHV thấp hơn. Bà me có nghề nghiêp là CBVC, công nhân có kiến thức cao hơn nhóm bà mẹ làm nghề buôn bán, nông dân, nội trợ, kết quả này tượng tự như nghiên cứu của Lê Thị Thanh Huyền [4]. Bên canh đó, bà me sinh sống tai phường Tây Lộc cũ̃ng có thực hành tốt hơn. Tây Lộc là một phường nằm gần trung tâm thành phố và có nền kinh tế-văn hóa-xã hội phát triển, vì vậy, các bà mẹ dễ dàng tiếp cận hơn với các cơ sở chăm sóc sức khỏe cũng như nhận được đầy đủ các dịch vụ về CSTS. Tìm thây mối liển quan giữa kiến thức và thực hành CSTS của bà mẹ, nhóm bà me có kiến thức tốt về CSTS có thực hành tốt cao hơn nhóm bà me có kiến thức chưa tốt. Mối liên quan này cũng được rất nhiều tác giả khác phát hiện trong nghiền cứu của mình [5], [8]. Chúng tôi cũng nhận thấy mối liên quan giữa số lần mang thai và số lần sinh con của các bà mẹ với thực hành về CSTS. Điều này có thể lý giải là do các thai phụ mang thai lần đầu có kiến thức tốt hơn, đi khám thai nhiều hơn, sử dụng nhiều hơn các dịch vụ CSTS, thực hành tốt các nội dung về dinh dương, lao động trong thời kỳ mang thai hơn các bà mẹ mang thai và sinh con từ lần thứ 2 trở lên.

\section{KẾT LUÂ̂N}

Nghiên cứu của chúng tôi cho thây khoảng $60 \%$ đối tượng có kiến thức và thực hành tốt về CSTS. Phụ nữ có TĐHV cao, nghề nghiệp là CBVC, công nhân, sinh con lần đầu có kiến thức và thực hành về CSTS tốt hơn. Đặc biệt, thực hành về các nội dung của CSTS tốt hơn ở những đối tượng có kiến thức về CSTS tốt. Do vậy, cần đặc biệt tăng cường thêm công tác truyên thông giáo dục sức khỏe, tư vấn cho phụ nữ trước và trong khi mang thai nhằm đảm bảo phụ nữ có kiến thức tốt về CSTS và thực hành có hiệu quả.

\section{TÀI LIỆU THAM KHẢO}

1. Bô Y Y tế. Hướng dẫn quốc gia về các dịch vụ chăm sỏc sức khỏe sinh sản. 2017. Hà Nội.

2. Bố Y Tế, Bộ Y Tế. Quyết định số $4177 / Q Đ-B Y T$ về việc phế duyệt kế hoạch hành động quốc gia về chăm sóc sức khỏe bà me, trẻ sơ sinh và trẻ em giai đoan 2016-2020. 2016. Hà Nôi.

3. Lê Thị Thu Huyên. Tình hình chằm sóc trước sinh tai thành phố Tuy Hòa năm 2010-2011. Luận văn tốt nghiệp chuyên khoa cấp I, Trường Đại học Y Dược Huế. 2011.

4. Lê Thị Thanh Huyền. Nghiên cứu kiến thức, thái đô và thực hành chăm sóc thai sản của các bà me các xã miền núi thuộc huyện Hòa Vang thành phổ Đà Nẵng năm 2015. Luận văn Thạc sĩ y học, Trường Đaai học Y Dược Huế. 2016.

5. Lê Nguyển Quang Thái. Nghiên cứu kiến thức và thực hành chăm sóc tiền sản ở thai phụ mang thai 3 tháng cuối thai kỳ tai xã Giai Xuân và thị trấn Phong Điên, thành phổ Cần Thơ năm 2016. Luận văn tốt nghiếp Bác sĩ $Y$ hơc dự phòng, Trường Đại học Y Yược Cân Thơ. 2017.

6. Nguyễn Chiến Thẳng. Nghiên cứu tình hình cung cấp và sử dụng dịch vụ chăm sóc thai sản tại huyện Cư Kuin, tỉnh Đăk Lăk năm 2012. Luận án chuyên khoa cấp II, Trường Đai họ Y Dược Huế. 2012.

7. Amanpreet $K$, Jagdeep $S$, et al. Knowledge and practices regarding antenatal care among mothers of infants in an urban area of Amritsar, Punjab. International Journal of Community Medicine and Public Health. 2018; 5(10): 4263-4267.

8. Patel BB, Gurmeet $\mathbf{P}$, et al. A study on knowledge and practices of antenatal care among pregnant women attending antenatal clinic at a Tertiary Care Hospital of Pune, Maharashtra. Medical Journal of Dr. D.Y. Patil University. 2016; 9(3): 354-362.

9. Tunçalp Ö, Pena-Rosas JP, et al. WHO recommendations on antenatal care for a positive pregnancy experience - going beyond survival. BJOG: An International Journal of Obstetrics \& Gynaecology. 2017; 124(6): 860-862. 